\title{
Correction to: Prevalence and Incidence of Developmental Disorders in Korea: A Nationwide Population-Based Study
}

\author{
Sung Sil Rah ${ }^{1} \cdot$ Soon-Beom Hong ${ }^{2} \cdot$ Ju Young Yoon ${ }^{3}$
}

Published online: 4 November 2020

(c) Springer Science+Business Media, LLC, part of Springer Nature 2020

\section{Correction to: Journal of Autism and Developmental Disorders https://doi.org/10.1007/s10803-020-04444-0}

Incorrect: In this study, customized data were used after approval of the Institutional Review Board of Seoul National University (IRB No. E1811/002-001) and the review committee of the NHISS (REQ0000020909).

Correct: In this study, customized data were used after approval of the Institutional Review Board of Seoul National University (IRB No. E1811/002-001) and the review committee of the NHISS (NHIS-2019-1-139).
Publisher's Note Springer Nature remains neutral with regard to jurisdictional claims in published maps and institutional affiliations.

The original article can be found online at https://doi.org/10.1007/ s10803-020-04444-0.

Ju Young Yoon

yoon26@snu.ac.kr

1 College of Nursing, Seoul National University, 103 Daehak-ro, Jongno-gu, Seoul 03080, Korea

2 Division of Child and Adolescent Psychiatry, Department of Psychiatry, College of Medicine, Seoul National University, 103 Daehak-ro, Jongno-gu, Seoul 03080, Korea

3 Research Institute of Nursing Science, Seoul National University, Seoul, Korea 